\title{
Manajemen Sekolah dalam Pengelolaan Kegiatan Guru Bahasa Indonesa di Sekolah Dasar
}

\author{
Murni Yanto \\ Institut Agama Islam Negeri (IAIN) Curup \\ murniyanto@iaincurup.ac.id
}

\begin{abstract}
The present study explained how the school management was in managingthe activities of Indonesia language teachers in elementary school. This wasa descriptive qualitative study. The subjects engaged were the principal, teachers, and elementary school committees. The data were garnered from interviews, observations and documentation. Subsequently, the data analysis used data reduction, data presentation, and drawing conclusion. The results of the current study showed that the school management in managing Indonesian elementary school teachers' activities includes: a) The elementary school management in terms program planning has been carried out resting upon the objectives and the elementary school plans, but the involvement of the community (parents) in formulating elementary school programs is still lacking. b) The elementary school management in the fields of students, educators, education staff and curriculum has been implemented but not yet been in an appropriate way. c) The elementary school management in the field of leadership has analyzed the potential of the school, creating conducive elementary school. d) Elementary school management in the fields of supervision and evaluation, curriculum development, the empowerment of education and teachers, and supervision programs have not been adequate as expected.
\end{abstract}

Keywords: Management, Management of activities, teachers, elementary school

Abstrak. Pada penelitian ini menerasikan bagaimanakah manajemen sekolah dalam pengelolaan kegiatan guru bahasa Indonesia di sekolah dasar. Penelitian ini juga deskriptif kualitatif, subjek yang akan diteliti ialah kepala sekolah, guru serta komite sekolah dasar, cara pengumpulan data melalui wawancara, observasi dan dokumentasi, dan analisis data yang digunakan reduksi data, penyajian data disertai dengan kesimpulan. Dari hasil penelitian ini

ESTETIK : Jurnal Bahasa Indonesia, vol. 3, no. 1, 2020

IAIN Curup - Indonesia | ISSN 2622-1810 (p); 2622-1829 (e)

DOI: $10.29240 /$ estetik.v3i1.1479 
menyatakan bahwa manajemen sekolah dalam pengelolaan kegiatan guru bahasa Indonesia sekolah dasar meliputi. a) manajemen di sekolah dasar pada perencanaan program sudah dilaksanakan seperti tujuan, rencana sekolah dasar, namun keterlibatan masyarakat (orang tua) dalam merumuskan program sekolah dasar masih kurang. b) manajemen sekolah dasar di bidang kesiswaan, pendidik, tenaga kependidikan dan kurikulum sudah dilaksanakan tetapi masih ada tidak sesuai. c) manajemen sekolah dasar pada bidang kepemimpinan sudah menganalisis potensi sekolah, menciptakan sekolah dasar yang kondusif. d) manajemen sekolah dasar pada bidang pengawasan dan evaluasi, pengembangan kurikulum, pendayagunaan pendidikan dan tenaga kependidikan, program pengawasan belum memadai dari harapan yang diinginkan.

Kata Kunci: Manajemen, Pengelolaan kegiatan, Guru, SD

\section{Pendahuluan}

Dalam Undang-undang Sistem Pendidikan Nasional (UU Nomor 20 Tahun 2001) Pasal 17 pendidikan dasar merupakan jenjang pendidikan yang melandasi jenjang pendidikan menengah. Artinya sekolah dasar dituntut untuk mengembangkan potensi siswa dan mempersiapkan siswa melanjutkan pendidikan ke jenjang yang lebih tinggi. Sekolah dasar adalah jenjang paling dasar pada pendidikan formal di Indonesia. Sekolah dasar merupakan salah satu satuan pendidikan yang penting. Peran sekolah dasar dalam mendidik siswanya sangat besar. Dalam melakukan kegiatan di sekolah perlu dilakukan manajemen. Manajemen adalah perencanaan, pengorganisasian, pengarahan, dan pengendalian (P4) sumber daya organisasi untuk mencapai tujuan secara efektif dan efisien. Sedangkan dalam arti sempit manajemen sekolah adalah perencanaan program sekolah, pelaksanaan program sekolah, kepemimpinan kepala sekolah, pengawasan/evaluasi, dan sistem informasi sekolah (Husaini Usman, 2010). Manajemen adalah serangkaian kegiatan yang didesain untuk mencapai tujuan organisasi dengan menggunakan sumber daya secara efisien dan efektif dan dilakukan dalam lingkungan yang senantiasa berubah dari waktu ke waktu. (Murniyanto, 2018). 
Manajemen sekolah dalam melakukan kegiatan sekolah diperlukan: 1) Kepala sekolah yang mampu menjadikan sekolah secara terus menerus menyesuaikan dengan kondisi internal dan eksternal yang paling mutakhir, 2) Kepala sekolah mampu mengkondisikan dan mengkoordinasikan seluruh sumber daya manusia untuk pencapaian tujuan; 3) Kepala sekolah dapat mempengaruhi sumber daya manusia dalam pencapaian tujuan jika melakukan pendekatan secara manusiawi, 4) Kepala sekolah harus menyadari bahwa, sumber daya manusia adalah satu komponen penting dalam perencanan organisasi, 5) dalam pengelolaannya, kepala sekolah harus mampu menegakkan hubungan yang serasi antara tujuan sekolah dengan perilaku sumber daya manusia yang ada, 6) Dalam meningkatkan efektivitas dan efisiensi sekolah, sangsi sumber daya manusia harus ditumbuhkan sebagai kekuatan utama. (Wahjosumidjo, 2011)

Dalam manajemen sekolah kepemimpinan yang baik, kepala sekola h harus mengelola sekolah dengan dibantu sumberdaya yang ada di sekolah. Kepala sekolah yang baik memiliki kriteria: 1) Memiliki wawasan jauh kedepan, 2) Memiliki kemampuan mengkoordinasikan dan menyerasikan seluruh sumber daya terbatas yang ada untuk memenuhi kebutuhan sekolah (yang umumnya tidak terbatas), 3) Memiliki kemampuan mengambil keputusan dengan terampil (cepat, tepat, cekat, dan akurat), 4) Memiliki kemampuan memobilisasi sumber daya yang ada dan mampu menggugah pengikutnya untuk melakukan hal-hal penting bagi tujuan sekolahnya, 5) Memiliki toleransi terhadap perbedaan setiap orang, akan tetapi sama sekali tidak toleran dengan orang-orang yang meremehkan kualitas, prestasi, standar, dan nilainilai, 6) Memiliki kemampuan memerangi musuh-musuh kepala sekolah yaitu ketidak pedulian, kecurigaan, tidak membuat keputusan, mediokrasi, imitasi, arogansi, pemborosan, kaku, dan bermuka dua dalam bersikap dan bertindak. (Daryanto,2011).

Keberhasilan seorang kepala sekolah dapat dilihat dengan mengetahui tingkat kepedulian kepala sekolah terlibat terhadap kedua orientasi meliputi: 1) apa yang dicapai oleh organisasi sekolah (organizational achievement) dan 2) pembinaan terhadap organisasi sekolah (organizational maintenance). Organizational achievement 
meliputi produksi, pendanaan, kemampuan adaptasi dengan programprogram inovatif, dan sebagainya. Sedang organizational maintenance, berkaitan dengan variabel kepuasan bawahan, motivasi, dan semangat kerja. (Wahjosumidjo,2011).

Penelitian terdahulu: Artiah, dkk, 2013, (Program studi pada guru sekolah dasar) dalam makalah manajemen sekolah menyatakan: Manajemen adalah Suatu keadaan terdiri dari proses yang ditunjukkan oleh garis (line) mengarah kepada proses perencanaan, pengorganisasian, kepemimpinan, dan pengendalian, yang mana keempat proses tersebut saling mempunyai fungsi masing-masing untuk mencapai suatu tujuan organisasi. Pada hakekatnya istilah manajemen pendidikan dan manajemen sekolah mempunyai pengertian dan maksud yang sama. Keduanya susah untuk dibedakan karena sering dipakai secara bergantian dalam pengertian yang sama. Apa yang menjadi bidang manajemen pendidikan adalah juga merupakan bidang manajemen sekolah. Demikian pula proses kerjanya ditempuh melalui fungsi-fungsi yang sama, yang diturunkan dari teori administrasi dan manajemen pada umumnya. Kepemimpinan adalah kekuasaan untuk mempengaruhi seseorang, baik dalam mengerjakan sesuatu atau tidak mengerjakan sesuatu, bawahan dipimpin bukan dengan jalan menyuruh.

Dalam rangka menjaga dan meningkatkan motivasi pendidik dan tenaga kependidikan, kepala sekolah memberikan motivasi bahwa tugas guru yang mulia maka harus ditaati dengan ibadah dan usaha untuk memberikan kesejahtraan pada para pendidikan dan tenaga kependidikan.

Kepala sekolah menyadari dalam pelaksanaan kegiatan guru di sekolah, kepala sekolah tidak bisa memaksa kehendak, kepala sekolah harus aktif berdiskusi dengan para guru, memberikan pemahaman kepada guru secara pelan kepada guru tentang, perencanaan program manajemen sekolah dasar, pelaksanaan progam manajemen sekolah dasar, kepemimpinan sekolah dasar, pengawasan dan evaluasi.

\section{Manajemen Pendidikan}


Manajemen adalah proses merencanakan, mengorganisasikan, memimpin dan mengendalikan usaha anggota-anggota organisasi serta pendayagunaan seluruh sumber daya organisasi dalam rangka mencapai tujuan yang telah ditetapkan (Wahjosumidjo, 2011).

Manajemen adalah proses perencanaan, pengorganisasian, pengarahan, dan pengendalian (P4) sumber daya organisasi untuk mencapai tujuan secara efektif dan efisien. (Daryanto, 2013). Manajemen adalah apa yang dilakukan oleh manajer. Dengan kata lain, manajemen merupakan proses mengkoordinir kegiatan agar efektif dan eflsien melalui orang lain. (Hery,2013). Hal ini berarti manajemen memerlukan beberapa orang yang punya tujuan yang sama dan saling bekerjasama untuk mencapai tujuan. Manajemen adalah proses mendesain dan mengelola lingkungan di mana individu mendesain bekerjasama dalam kelompok efektif dalam mencapai tujuan (Murniyanto, 2017).

Pendidikan adalah usaha sadar dan terencana untuk mewujudkan suasana belajar dan proses pembelajaran agar peserta didik secara aktif mengembangkan potensi dirinya untuk memiliki kekuatan spiritual keagamaan, pengendalian diri, kepribadian, kecerdasan, akhlak mulia, serta keterampilan yang diperlukan dirinya, masyarakat bangsa dan Negara.

Manajemen pendidikan secara umum sebagai pengaturan. penataan, pengelolaan pendidikan. Dalam arti umum ini, kegiatan yang dikategorikan sebagai manajemen pendidikan adalah mengorganisasikan pendidikan, yaitu mengatur (menata) kegiatan penyelenggaraan pendidikan kedalam unit-unit (satuan) organisasi pendidikan menurut jenis (pendidikan umum, kedinasan. keagamaan, kejuruan) dan jenjang (pra sekolah, dasar, menengah, tinggi). (Tatang, 2013).

Manajemen pendidikan sebagai seni dan ilmu mengelola sumber daya pendidikan untuk mewujudkan suasana belajar agar siswa aktif untuk mengembangkan potensi dirinya yang diperlukan dirinya, masyarakat, bangsa. dan negara. Manajemen pendidikan juga dapat diartikan sebagai proses perencanaan, pengorganisasian, pelaksanaan. pengendalian sumber daya pendidikan untuk mencapai tujuan 
pendidikan. Manajemen pcndidikan di Indonesia selalu mengalami perkembangan. (Daryanto, 2013)

Berdasarkan pendapat para ahli di atas, dapat disimpulkan bahwa manajemen pendidikan adalah ilmu yang mempelajari cara mengelola sumber daya pendidikan untuk mencapai tujuan pendidikan yang telah ditetapkan.

\section{Faktor-Faktor yang Mempengaruhi Manajemen Pendidikan}

Yang mempengaruhi manajemen pendidikan: l) manajer pendidikan, 2) organisasi pendidikan, 3) lingkungan, dan 4) sistem pendidikan nasional. (Husaini Usman,2010)

Manajer pendidikan. Manusia dalam organisasi tidak terlepas dari sistem yang telah dibuat di organisasi tersebut. Sistem itu dibuat berdasarkan kesepakatan anggotanya. Manajer pendidikan adalah salah satu yang paling berperan dalam pembentukan sistem tersebut. Oleh karena seorang manajer diharapkan adalah orang yang berwawasan luas dan mampu mengelola organisasi pendidikan.

Organisasi pendidikan. Manusia sebagai manajer tidak bisa terlepas dengan wadahnya tempat dia berinteraksi yaitu organisasi. Organisasi dapat berupa lembaga pendidikan formal, non formal, maupun informal.Didalamorganisasiadamanusia yang saling berinteraksi. Organisasi sebagai wadah selayaknyadapat menyatukan langkah para anggotanya untuk mencapai satu tujuan.

Lingkungan. Lingkungan fisik yang kondusif dan lengkap akan turut membantu keberhasilan manajemen pendidikan. Lingkungan non fisik berupa komunikasi yang baik, situasi dan kondisi yang kondusif akan memperlancar proses manajemen pendidikan sehingga tujuan pendidikan akan lebih mudah tercapai.

Sistem pendidikan nasional adalah keseluruhan komponenen pendidikan yang saling terkait untuk mencapai tujuan pendidikan nasional. Sistem pendidikan nasional juga merupakan pedoman bagi seorang manajer pendidikan dalam berperilaku baik secara individu maupun kelompok agar organisasi menjadi tertib. Ketertiban organisasi penting agar dapat menyamakan persepsi seluruh anggota organisasi 
dalam perencanaan, pelaksanaan, pengelolaan, dan pengawasan kegiatan. (Husaini Usman, 2010)

Gambar 1: Faktor-faktor yang mempengaruhi manajemen pendidikan.

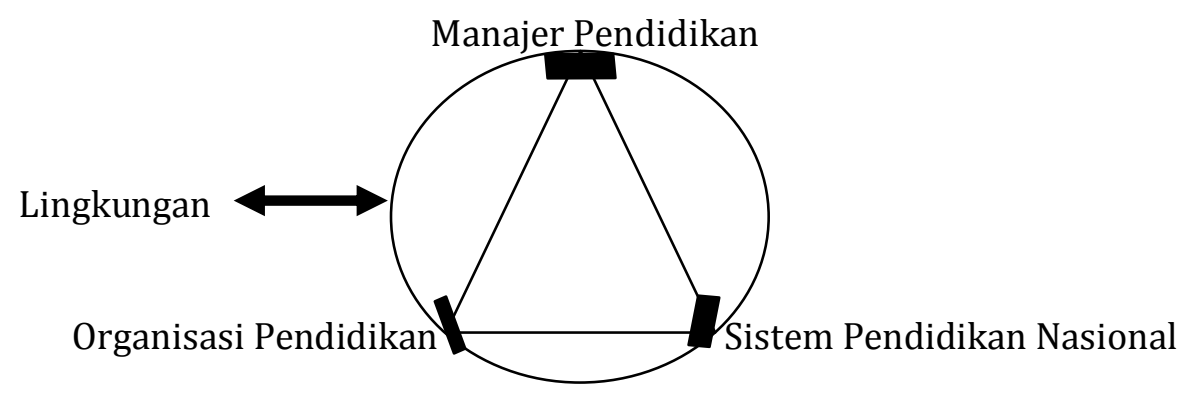

Dalam manajemen pendidikan terdapat suatu sistem yang terdiri dari beberapa komponen yang saling berhubungan dan saling mempengaruhi. Faktor-faktor yang mempengaruhi manajemen pendidikan yaitu: 1) pendidik, 2) peserta didik, 3) materi atau bahan didikan yaitu kurikulum, 4) sarana dan prasarana pendidikan, dan 5) tujuan pendidikan.(Tatang,2013)

\section{Metode}

Penelitian kualitatif merupakan metode-metode untuk mengeksplorasi dan memahami makna yang (oleh sejumlah individu atau sekelompok orang) dianggap berasal dari masalah sosial atau kemanusiaan. Alasan yang melatarbelakangi peneliti menggunakan pendekatan kualitatif adalah untuk memperoleh informasi di lapangan cenderung membutuhkan penjelasan secara apa adanya dan perhatian penelitian lebih tertuju pada pemahaman bermakna terkait manajemen sekolah dalam pengelolaan kegiatan guru bahasa Indonesia di sekolah dasar dengan tidak mengesampingkan keadaan di lapangan. (Jhon W. Creswell, 2010). Pendekatan penelitian yang digunakan peneliti adalah pendekatan kualitatif. Teknik penelitian melalui observasi, wawancara dan dokumentasi. Subjek dan objek penelitian adalah kepala sekolah, guru, dan komite sekolah dasar. Narasumber, informan dan teman guru. Instrumen penelitian dikembangkan meliputi pedoman observasi dan pedoman wawancara. Pengumpulan data melalui wawancara, observasi dan dokumentasi. 


\section{Hasil dan Pembahasan}

\section{Program guru Sekolah Dasar}

Pada sekolah dasar membuat perencanaan sekolah setiap akan memasuki tahun ajaran baru. Caranya adalah pembuatan rencana kerja guru dan sekolah adalah dengan mengundang semua dewan guru, komite sekolah, dan perwakilan orang tua murid dalam rapat pleno,rapat dewan guru dan komite sekolah dan juga mengundang tokoh masyarakat sekitar sekolah. Hal ini menunjukkan bahwa sekolah menerapkan musyawarah berbasis sekolah dalam pengelolaan sekolah. Manajemen Berbasis Sekolah yaitu ada pengambilan keputusan di sekolah yang partisipatif dan demokratis. Rencana Kegiatan dan Anggaran Sekolah memuat ketentuan yang jelas mengenai kesiswaan, kurikulum dan kegiatan pembelajaran. serta peran serta masyarakat dan kemitraan sekolah. (Raihani, 2011)

\section{Pelaksanaan Program guru Sekolah Dasar}

Dalam Pelaksanaan Program guru Sekolah dari analisis hasil observasi, wawancara, dan dokumentasi maka dapat ditarik kesimpulan bahwa manajemen sekolah dasar dalam pelaksanaan program yang sudah terlaksana adalah membuat pedoman yang mengatur berbagai aspek pengelolaan secara tertulis. Dari beberapa kali observasi di sekolah, peneliti berkesimpulan bahwa sekolah memiliki pedoman pengelolaan berupa kurikulum sekolah, kalender pendidikan, struktur organisasi, peraturan akademik, dan tata tertib sekolah.

Semua pimpinan, pendidik, dan tenaga kependidikan mempunyai tugas dan wewenang yang jelas. Hal tersebut dapat dilihat dalam struktur organiasasi sekolah yang dipasang pada papan di ruang guru. Di antara tugas kepala sekolah adalah sebagai edukator, manajer, administrator, supervisor, pemimpin/leader, dan motivator. Salah satu indikator kepala sekolah yang efektif adalah ada kejelasan pendelegasian tugas antara kepala sekolah, guru, dan staf. (Tatang,2013). Pada atmosfer kerja yang kondusif untuk meningkatkan performa sekolah. (Raihani,2011) 
Kepala sekolah melibatkan warga dan masyarakat pendukung sekolah dalam mengelola sekolah dengan cara mengadakan pertemuan dengan paguyuban wali murid dan pengurus komite sekolah. Sekolah mampu menjalin hubungan yang harmonis dengan masyarakat. Salah satu kriteria kepala sekolah yang efektif adalah mampu menjalin hubungan yang harmonis dengan masyarakat sehingga dapat melibatkan mereka secara aktif dalam rangka mewujudkan tujuan pendidikan dan sekolah. (Imam Musbiki, 2013)

Pedoman pengelolaan bidang sarana dan prasarana serta bidang keuangan dan pembiayaan masih sulit. Hal ini menunjukkan bahwa sosialisasi pedoman pengelolaan bidang sarana dan prasarana, serta bidang keuangan dan pembiayaan masih kurang optimal.

\section{Kepemimpinan Sekolah Dasar}

Kepala sekolah juga merumuskan tujuan dan target mutu yang akan dicapai sekolah yang termuat dalam kurikulum sekolahdasar. Dalam merumuskan tujuan dan target mutu yang akan dicapai, sekolah memulainya dengan evaluasi dan refleksi keadaan sekolah dasar sebelumnya. Salah satu ciri kepala sekolah yang efektif adalah kepemimpinan yang memulai kepemimpinannya dengan introspeksi dan refleksi. Sekolah juga menganalisis tantangan, peluang, kekuatan, dan kelemahan sekolah dengan mencari data yang diperlukan. (Tatang, 2013).

Dalam rangka menjaga dan meningkatkan motivasi pendidik dan tenaga kependidikan, kepala sekolah memberi motivasi bahwa tugas gurusekolahdasar adalah tugas yang mulia maka harus diniati dengan ibadah dan berusaha untuk memberikan kesejahteraan pada para pendidik dan tenaga kependidikan. Kepala sekolah juga memberikan penghargaan kepada guru sekolahdasaryang berprestasi dengan cara memberikan selamat dan pada saat upacara bendera diumumkan kepada warga sekolahdasar. Kepala sekolah mampu menyelesaikan tugas dan pekerjaan sesuai dengan waktu yang telah ditentukan. Salah satu kriteria kepala sekolah yang efektif adalah kepala sekolah yang dapat menyelesaikan tugas dan pekerjaan sesuai dengan waktu yang telah ditentukan. (Imam Musbiki, 2013). 


\section{Pengawasan dan Evaluasi Sekolah dasar}

Berdasarkan analisis hasil observasi, wawancara, dan dokumentasi maka dapat disimpulkan bahwa manajemen sekolah terhadap pengawasan dan evaluasi yang sudah terlaksana adalah pengawasan sekolah, evaluasi terhadap sekolah guru dasar, evaluasi dan pengembangan kurikulum, evaluasi pendayagunaan pendidikan dan kependidikan. Program pengawasan sekolah dasar sudah terlaksana tapi belum optimal. Hal ini dikarenakan kesibukan dari kepala sekolah yang mempunyai banyak kegiatan di luar sekolah.

Evaluasi diri sekolah dasar yang dilakukan berlangsung sekali dalam setahun, yaitu pada akhir tahun. Evaluasi dan pengembangan kurikulum sekolah melibatkan banyak pihak termasuk komite sekolah. Evaluasi pendayagunaan pendidik dan tenaga kependidikan didasarkan pada kemampuan dan kinerja guru di sekolah.

\section{Kesimpulan}

Dari hasil penelitian dan pembahasan mendeskripsikan manajemen sekolah dalam pengelolaan kegiatan guru bahasa Indonesia di sekolah dasar sebagai berikut: 1) Manajemen sekolah dasar dalam perencanaan program sudah dilakukansepertirencana kerja sekolah. Dalam merumuskan rencana kerja sekolah, pihak sekolah sudah berupaya mengundang komite maupun orang tua siswa agar membantu. Namun keterlibatan orang tua siswa masih kurang. Penyusunan rencana kerja tahunan dinyatakan dalam dokumen Rencana Kegiatan dan Anggaran Sekolah dan disosialisasikan kepada pihak-pihak yang berkepentingan seperti gurusekolahdasar dan komite sekolah lewat pertemuan-pertemuan yang sudah disiapkan di sekolah. 2) Manajemen sekolah dasar dalam pelaksanaan program kerja sudah terlaksana adalah dalam bidang kesiswaan, bidang kurikulum, dan bidang pendidik dan tenaga kependidikan. Budaya dan lingkungan sekolah cukup kondusif untuk kegiatan belajar mengajar. Sekolah menjalin hubungan yang baik dengan masyarakat dan kemitraan sekolah. Sedangkan pelaksanaan program sekolah yang belum memadai adalah melaksanakan program yang tidak direncanakan. 3) Manajemen sekolah dasar dalam kepemimpinan sudah terlaksana adalah merumuskan 
tujuan dan target sekolah yang akan dicapai dengan mengevaluasi kegiatan sebelumnya. Kepala sekolah menganalisis dan mangetahui tantangan, peluang, kekuatan, dan kelemahan sekolah dasar. Kepala sekolah dasar memberikan motivasi kepada para guru agar mengajar dengan dilandasi niat beribadah. Kepala sekolah dasar memberikan penghargaan kepada pendidik yang berprestasi dengan cara diumumkan saat upacara bendera. KepalaSekolah berusaha menciptakan lingkungan pembelajaran yang efektif dengan berusaha melengkapi sarana dan prasarana yang dibutuhkan. Guru sekolah dasar memberikan teladan kepada warga sekolah tentang kedisiplinan. Sekolah pun sudah berusaha menjalin hubungan yang harmonis dengan orang tua peserta didik, masyarakat, dan komite sekolah. Sedangkan hal yang belum terlaksana adalah supervisi secara langsung. Kepala sekolahdasar hanya mengawasi kegiatan pembelajaran dengan cara berkeliling sekolah tanpa menunggui kegiatan guru kelas. 4) Manajemen sekolah dasar dalam kegiatan pengawasan dan evaluasi sudah terlaksana adalah evaluasi sekolah.

Evaluasi/pengembangan kurikulum, dan evaluasi pendayagunan pendidik dan tenaga kependidikan yang dilaksanakan setiap akhir tahun ajaran (setahun sekali). Sedangkan program pengawasan sekolah sudah terlaksana namun belum optimal. Hal ini dikarenakan kepala sekolahdasar mempunyai banyak kegiatan baik di sekolah dan di luar sekolah. Karena kesibukannya di luar sekolah, maka kepala sekolah dasarmengawasi kegiatan pembelajaran di sekolah tidak sampai akhir jam pelajaran.

\section{Daftar Pustaka}

Daryanto. (2011). Kepala Sekolah Sebagai Pemimpinan Pembelajaran. Yogyakarta: Penerbit Gava Media.

Hery. (2013). Pengatur Manajemen (Cara Cepat dan Mudah Memahami). Jakarta: Penerbit Gava Media.

Husaini Usman. (2010). Manajemen (Teori, Praktik, dan Riset Pendidikan). Edisi 3. Jakarta: Bumi Aksara.

Iman Musbikin. (2013). Menjadi Kepala Sekolah Yang Hebat. Pekanbaru: 
Zanafa Pubslihing.

Jhon W. Creswell (2010). Research Design: Pendekatan Kualitatif, Kuantitatif, dan Mized. Edisi ketiga. Penerjemah: Achmad Fawaid. Yogyakarta: Pustaka Pelajar.

Murniyanto. (2018). Manajemen dan Mutu Pembelajaran Bahasa Indonesia Di SMP Negeri 4 Rejang Lebong. Tadbir : Jurnal Studi Manajemen Pendidikan, 2 (1), 71-88. doi: http://dx.doi.org/10.29240/jsmp.v2i1.388

Murniyanto. (2017). Manajemen Perpustakaan Madrasah Ibtidaiyah Negeri 1 Rejang Lebong. AR-RIAYAH : Jurnal Pendidikan Dasar, 1(2), 189-204. doi:http://dx.doi.org/10.29240/jpd.v1i2.319.

Tatang M. Amirin. (2013). Manajemen Pendidikan. Yogyakarta: UNY Press.

Undang-Undang Dasar Negara Republik Indonesia Tahun 1945.

Undang-undang Nomor 20. Tahun 2003 Tentang Sistem Pendidikan Nasional.

Wahjosumidjo. (2011). Kepemimpinan Kepala Sekolah . Jakarta: Rajawali Pers. 